\title{
Phenolic Accumulation in Hybrid Primrose and Pigment Distribution in Different Flower Segments
}

\author{
Valentina Schmitzer ${ }^{1}$ \\ Department of Landscape Architecture, Biotechnical Faculty, University of Ljubljana, Jamnikarjeva \\ 101, SI-1000 Ljubljana, Slovenia \\ Maja Mikulic-Petkovsek, Franci Stampar, and Vlasta Cunja \\ Department of Agronomy, Biotechnical Faculty, University of Ljubljana, Jamnikarjeva 101, SI-1000 \\ Ljubljana, Slovenia
}

\begin{abstract}
Additional INDEX words. Primula $\times$ polyantha, flavonols, chlorophyll, total phenolic content, anthocyanins, flower parts
Abstract. Detailed anthocyanin and flavonol profiles were investigated in three flower segments of four different hybrid primrose (Primula $\times$ polyantha) cultivars, and individual compounds were identified using high-performance liquid chromatography (HPLC)/mass spectrometry system. Chlorophyll a and b and total carotenoids were evaluated spectrophotometrically in the corolla tube (CT), and distal and proximal flower segments, and the color of each segment was assessed with a colorimeter. Chlorophyll b predominated over chlorophyll a in all flower segments, and the highest total chlorophyll levels were found in the CTs. Sixteen different anthocyanins (glycosides of cyanidin, delphinidin, peonidin, petunidin, malvidin, and rosinidin) were identified in red, pink, and blue flower extracts. Distal segments of the red hybrid and proximal segments of the pink hybrid accumulated highest levels of total anthocyanins, and no red pigments were detected in yellow-flowered hybrid primrose. Six groups of flavonols (40 individual compounds in total) were detected in different flower segments of four hybrid primrose cultivars. Yellow primrose was characterized by the greatest diversity of flavonols as it contained four isorhamnetin, five kaempferol, six laricitrin, three myricetin, six quercetin, and six syringetin glycosides. On the other hand, the smallest variety of flavonols was detected in pink hybrids. Total phenolic content (TPC) was lowest in the CT (yellow $>$ red $>$ pink), significantly higher in the proximal flower segment (yellow $>$ red $>$ pink), and highest in the distal part of the primrose petal (yellow $>$ pink $>$ red).
\end{abstract}

Primula is a genus of herbaceous plants widely spread and enthusiastically investigated by botanists for several 100 years. It is the largest genus of the Primulaceae, encompassing more than 420 species of temperate and alpine regions of the northern hemisphere (Markelov et al., 2015; Richards, 2003). Some species also inhabit mountains at tropical latitudes (Fico et al., 2007; Vitalini et al., 2011).

The rosette-forming plants are mostly valued for their ornamental purposes, and numerous hybrids derive from several Primula species: P. elatior, P. juliae, P. sieboldii, $P$. veris, and P. vulgaris (Richards, 2003). The latter has been hybridized for many centuries and is one of the genetic ancestors of the horticultural hybrid polyanthus $(P$. $\times$ polyantha). This hybrid primrose is a natural cross between $P$. veris (cowslip) and $P$. vulgaris (common primrose), which blooms in a wide range of colors and hues and often produces multicolored flowers (Scott-Moncrieff, 1930).

Flower color is one of the chief features of ornamental plants, and it is shaped by their biochemistry, specifically the distribution and composition of secondary metabolites in plastids and vacuoles (Zhao and Tao, 2015). Anthocyanins, carotenoids, chlorophylls, and flavonols are the major contributors to astonishing color diversity of flowers, and their content often changes during flower senescence (Schmitzer et al., 2010; Slatnar et al., 2013; Sood and Nagar, 2003). Moreover, petal

Received for publication 17 Jan. 2017. Accepted for publication 20 Mar. 2017. This work is part of program Horticulture No. P4-0013-0481, funded by the Slovenian Research Agency (ARRS).

The authors are not members of ASHS

${ }^{1}$ Corresponding author. E-mail: valentina.schmitzer@bf.uni-lj.si. structure, $\mathrm{pH}$ level of the cell sap, copigmentation with other phenolics, and metal ions define the color tone of various ornamentals (Cunja et al., 2014; Eugster and Markifischer, 1991). However, flowers are not solely ornamental, and pigments serve other purposes than attracting pollinators or acting as ultraviolet-protective compounds (Mori et al., 2005). For example, christmas rose (Helleborus nigra) flowers accumulate

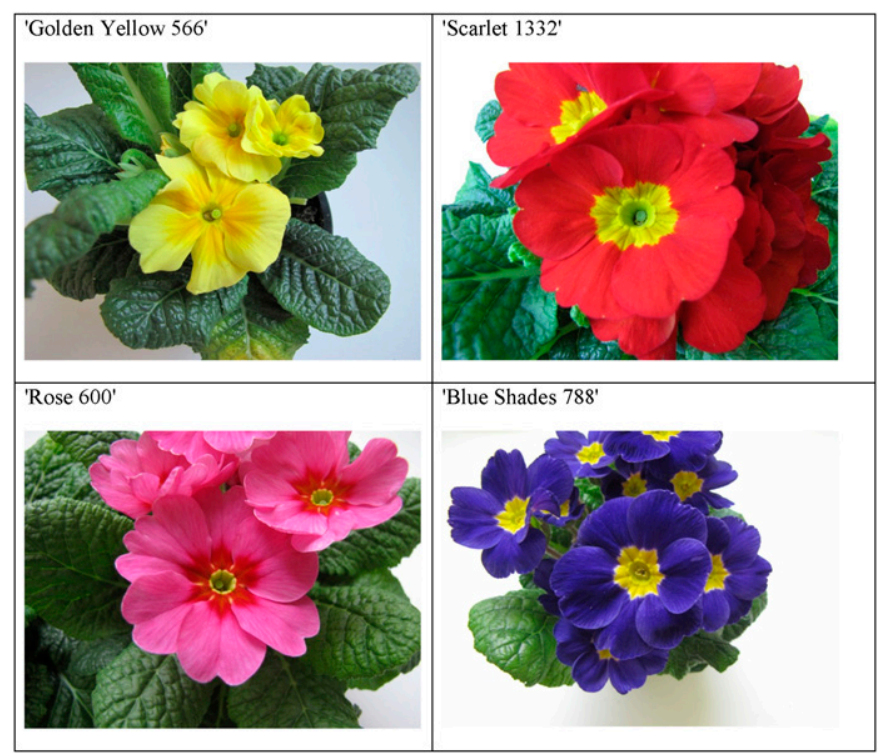

Fig. 1. Hybrid primrose cultivars used for flower analysis. 


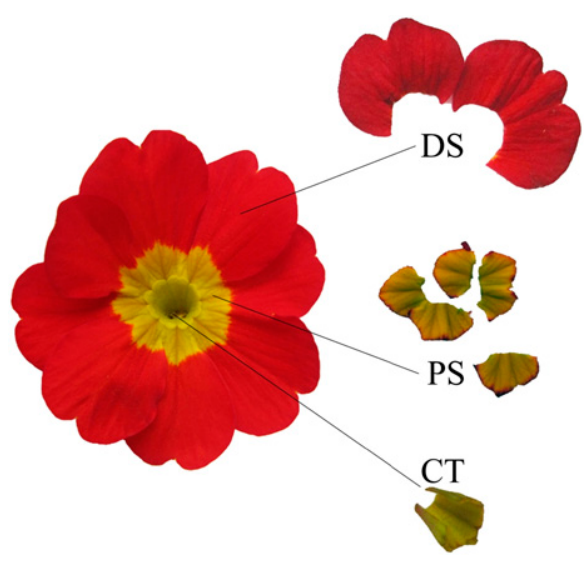

Fig. 2. Sampling procedure of different flower segments of hybrid primrose $(\mathrm{DS}=$ distal petal segment; $\mathrm{PS}=$ proximal petal segment; and $\mathrm{CT}=$ corolla tube).

chlorophyll and represent an important photosynthetic organ, which produces metabolites to support the developing seeds (Salopek-Sondi et al., 2002; Schmitzer et al., 2013). Is a similar strategy employed by the multicolored and often green streaked flowers of the hybrid primrose?

The lack of information on the secondary metabolite profile of $P$. xpolyantha has intrigued us to identify pigment distribution in various cultivars and moreover in three different flower segments. Species of the Primula genus have previously been biochemically assessed, particularly the flavonoid content of $P$. veris (Huck et al., 2000), P. hirsuta, P. auricula, P. spectabilis, and $P$. daonensis (Fico et al., 2007; Vitalini et al., 2011) leaves and flowers, and saponins in rhizomes and roots of various primrose species (Morozowska, 2004; Müller et al., 2006) often served as biomolecular factors in their characterization. However, a detailed study on pigment composition of the hybrid primrose has not been conducted to our knowledge. Clarification of the biodiversity of anthocyanins and flavonols is needed to pinpoint the compounds, which affect the vast color range of this ornamental hybrid. The study thus provides specific knowledge on petal phenolic profile of hybrid primroses and serves as a launch pad for hybridization and cultivar breeding for explicit color traits such as blotched or variegated flower forms.

\section{Material and Methods}

Plant material. Four cultivars of $P$. xpolyantha were obtained from a local nursery and transferred to the laboratory facility of Biotechnical Faculty, Ljubljana, Slovenia. Cultivars were chosen to best represent the variety of color hues and the popularity of hybrid primroses, and thus a yellow (Golden Yellow 566), red (Scarlet 1332), pink (Rose 600), and blue (Blue Shades 788) cultivars were used for the analysis (Fig. 1). Different color hues of $P . \times$ polyantha were selected to investigate the complexity, abundance, and content levels of different phenolic constituents (with an emphasis on anthocyanins and flavonols) in primrose hybrids. Fifteen plants per cultivar were analyzed, and three fully opened flowers were sampled on each plant (45 flowers per cultivar). Colorimetric measurements and phenolic profiling were performed on three distinct flower segments: distal petal segment (DS), proximal petal segment (PS), and CT (Fig. 2). Colorimetric analyses were performed on fresh flower segments, which were then shock-frozen in liquid nitrogen and stored in a deep freezer $\left(-20{ }^{\circ} \mathrm{C}\right)$ until analyses of secondary metabolites and photosynthetic pigments.

Flower COLOR MEASUREMENTS. The color of three different flower segments (DS, PS, and CT) was measured with a portable colorimeter (CR-10 Chroma; Minolta, Osaka, Japan) calibrated with a white standard calibration plate before use. In CIE (Commission Internationale de l'Éclairage) $L^{*} a^{*} b^{*}$ system of color

Table 1. A list of anthocyanins identified in red, pink, and blue hybrid primrose cultivars, standards used for their calculations, and mass spectrometry specifications.

\begin{tabular}{|c|c|c|c|c|c|c|c|}
\hline \multirow[b]{2}{*}{ Anthocyanin } & \multirow[b]{2}{*}{$\begin{array}{l}\text { Standard } \\
\text { used }^{z}\end{array}$} & \multicolumn{4}{|c|}{ Flower color } & \multicolumn{2}{|c|}{$\mathrm{MS}^{\mathrm{y}}$ specifications } \\
\hline & & Red & Pink & Blue & $\begin{array}{c}{[\mathrm{M}+\mathrm{H}]^{+}} \\
(\mathrm{m} / \mathrm{z})\end{array}$ & $\begin{array}{c}\mathrm{MS}^{2}\left[\mathrm{M}^{+}\right] \\
(\mathrm{m} / \mathrm{z})\end{array}$ & $\begin{array}{c}\mathrm{MS}^{3}\left[\mathrm{M}^{+}\right] \\
(\mathrm{m} / \mathrm{z})\end{array}$ \\
\hline Cy-3-galactoside & Cy-3-gal & $\mathrm{x}$ & & & 449 & 287 & \\
\hline Cy-3-glucoside & Cy-3-glu & $\mathrm{x}$ & $\mathrm{x}$ & $\mathrm{x}$ & 449 & 287 & \\
\hline Del-3-glucoside & Del-3-glu & & & $\mathrm{x}$ & 465 & 303 & \\
\hline Pet-3-galactoside & Cy-3-glu & & & $\mathrm{x}$ & 479 & 317 & \\
\hline Pet-3-glucoside & Pet-3-glu & & & $\mathrm{x}$ & 479 & 317 & \\
\hline Dimethylpet dihexoside & Pet-3-glu & & & $\mathrm{x}$ & 669 & 507 & 345 \\
\hline Dimethylpet hexoside & Pet-3-glu & & & $\mathrm{x}$ & 507 & 345 & 317 \\
\hline Peo-3-galactoside & Peo-3-glu & $\mathrm{x}$ & $\mathrm{x}$ & $\mathrm{x}$ & 463 & 301 & \\
\hline Peo-3-glucoside & Peo-3-glu & $\mathrm{x}$ & $\mathrm{x}$ & $\mathrm{x}$ & 463 & 301 & \\
\hline Peo-dihexoside 1 & Peo-3-glu & $\mathrm{x}$ & $\mathrm{x}$ & & 625 & 301 & \\
\hline Peo-dihexoside 2 & Peo-3-glu & & $\mathrm{x}$ & $\mathrm{x}$ & 625 & 301 & \\
\hline Malv-3-galactoside & Malv-3-glu & & & $\mathrm{x}$ & 493 & 331 & \\
\hline Malv-3-glucoside & Malv-3-glu & & & $\mathrm{x}$ & 493 & 331 & \\
\hline Malv dihexoside & Malv-3-glu & & & $\mathrm{x}$ & 655 & 331 & \\
\hline Ros hexoside & Cy-3-glu & $\mathrm{x}$ & & & 477 & 315 & 287 \\
\hline Ros dihexoside & Cy-3-glu & $\mathrm{x}$ & $\mathrm{x}$ & & 639 & 477 & 315 \\
\hline
\end{tabular}

${ }^{\mathrm{z}} \mathrm{Cy}=$ cyanidin $;$ Del $=$ delphinidin $;$ Pet $=$ petunidin $; \mathrm{Peo}=$ peonidin $; \mathrm{Malv}=$ malvidin $;$ Ros $=$ rosinidin; glu $=$ glucoside $;$ gal $=$ galactoside .

${ }^{\mathrm{y}} \mathrm{MS}=$ mass spectrometer; $[\mathrm{M}+\mathrm{H}]^{+}(\mathrm{m} / \mathrm{z})=$ molecular ion $+\mathrm{H}$ ion (mass charge ratio); $\mathrm{MS}^{2}\left[\mathrm{M}^{+}\right]$ $(\mathrm{m} / \mathrm{z})=$ mass spectrometrometry to the second degree; $\mathrm{MS}^{3}\left[\mathrm{M}^{+}\right](\mathrm{m} / \mathrm{z})=$ mass spectrometrometry to the third degree. representation, the $L^{*}$ value corresponds to a dark-bright scale and represents the relative lightness of the sample $(0=$ black, $100=$ white $)$. The coordinates $a^{*}$ and $b^{*}$ vary from -128 to +128 and relate to green to purple and blue to yellow hues, respectively (Kumpanenko et al., 2014). The hue angle $\left(h^{\circ}\right)$ is expressed in degrees from 0 to $360\left(0^{\circ}=\mathrm{red}\right.$, $90^{\circ}=$ yellow, $180^{\circ}=$ green, and $360^{\circ}=$ blue $)$. Color was measured in three replicates on each flower segment to ensure equal measurement conditions.

P I GMENT AND PHENOLIC IDENTIFICATION. The content of chlorophyll a and b, total carotenoids, and total pigments was evaluated according to the method by Wellburn (1994). Microtubes $(1.5 \mathrm{~mL})$ were filled with $0.5 \mathrm{~mL}$ dimethyl sulfoxide (DMSO). A single 4-mm-segment disc combined with crystals of magnesium hydroxide carbonate was mashed in the tube for better extraction. DMSO solution 
$(0.5 \mathrm{~mL})$ was added, and samples were left in a water bath $\left(65^{\circ} \mathrm{C}\right)$ in the dark for $2 \mathrm{~h}$. The samples were cooled to room temperature, decanted into vessels, and absorption was measured on a spectrometer (Lambda Bio; PerkinElmer, Waltham, MA) at $480 \mathrm{~nm}$ (carotenoids), $649 \mathrm{~nm}$ (chlorophyll b), and $665 \mathrm{~nm}$ (chlorophyll a). Concentrations of photosynthetic pigments in extracts were determined according to Wellburn (1994) equations.

Extraction of individual anthocyanins and flavonols was performed according to the method of Slatnar et al. (2013) with some modifications. About $0.3 \mathrm{~g}$ of powdered petal segments were extracted with $2 \mathrm{~mL}$ methanol containing $3 \%(\mathrm{v} / \mathrm{v})$ formic acid and $1 \%(\mathrm{w} / \mathrm{v}) 2,6$-di-tert-butyl-4methylphenol (BHT) in an ultrasonic bath for $1 \mathrm{~h}$. Samples were centrifuged ( $7 \mathrm{~min}, 12,000 \mathrm{~g}_{\mathrm{n}}$ ), filtered through a polyamide filter (Chromafil AO-45/25; Macherey-Nagel, Düren, Germany), and analyzed on an HPLC system (Thermo Finnigan Surveyor; ThermoFisher Scientific, San Jose, CA) with a diode array detector at $350 \mathrm{~nm}$ (flavonols) and $530 \mathrm{~nm}$ (anthocyanins). The column was a HPLC column $(150 \times 4.6 \mathrm{~mm}, \mathrm{C} 18$, Gemini $3 \mu$; Phenomenex, Torrance, CA) operated at $25^{\circ} \mathrm{C}$. The injection volume was $20 \mu \mathrm{L}$, and the flow rate was maintained at $1 \mathrm{~mL} \cdot \mathrm{min}^{-1}$. The elution solvents were aqueous $1 \%$ formic acid and $3 \%$ acetonitrile (A) in water and $100 \%$ acetonitrile (B). Samples were eluted according to the linear gradient described by Marks et al. (2007). All individual phenolic compounds were identified using a mass spectrometer (LCQ Deca XP MAX; ThermoFisher Scientific) with electrospray ionization operating in negative (flavonols) and positive (anthocyanins) ion mode using mass spectrometrometry to the second degree $\left(\mathrm{MS}^{2}\right)$ scanning from $\mathrm{m} / \mathrm{z} 115$ to 1200 . The injection volume was $10 \mu \mathrm{L}$, and the flow rate $1 \mathrm{~mL} \cdot \mathrm{min}^{-1}$. Compounds were quantified with the use of external standards or similar compounds (Tables 1 and 2) and expressed as micrograms per gram fresh weight (FW).

Determination of total phenolic CONTENT. A similar protocol was used for the extraction of total phenols from petal segments as for individual phenolics, but no BHT was added to the solution. TPC of extracts was assessed by the Folin-Ciocalteu phenol reagent method described by Singleton et al. (1999). To $100 \mu \mathrm{L}$ of the sample extracts [diluted 1:4 (v/v) with methanol], $6 \mathrm{~mL}$ double distilled water and $500 \mu \mathrm{L}$ Folin-Ciocalteu reagent were added. The extraction followed the procedure described by
Mikulic-Petkovsek et al. (2015). The absorption was measured on a Lambda Bio spectrometer at $765 \mathrm{~nm}$ in five replications. Total phenolic content was expressed in milligrams gallic acid equivalents (GAE) per $100 \mathrm{~g}$ FW of flowers.

Statistical analysis. Statgraphics Plus 4.0 program (Manugistics, Rockville, MD) was used for data analysis. The differences in analyzed parameters were evaluated among individual petal segments (DS, PS, and CT) of different hybrid primrose cultivars (yellow, red, pink, and blue) as well as among three petal segments of an individual cultivar using oneway analysis of variance. Probability values of less than 0.05 
Table 3. Colorimetric parameters measured in three flower segments of four hybrid primrose cultivars.

\begin{tabular}{|c|c|c|c|c|c|}
\hline \multirow[b]{2}{*}{ Color } & \multirow[b]{2}{*}{ Flower segment $^{\mathrm{z}}$} & $a^{*}$ & $b^{*}$ & $h^{\circ}$ & $L^{*}$ \\
\hline & & \multicolumn{4}{|c|}{$($ mean $\pm \mathrm{SE})$} \\
\hline \multirow[t]{3}{*}{ Yellow } & $\mathrm{DS}$ & $6.22 \pm 0.72 b^{y}$ & $93.35 \pm 1.34 \mathrm{a}$ & $86.5 \pm 0.3 \mathrm{~b}$ & $79.7 \pm 0.5 \mathrm{a}$ \\
\hline & PS & $16.32 \pm 1.32 \mathrm{a}$ & $83.08 \pm 2.81 \mathrm{~b}$ & $79.3 \pm 0.6 \mathrm{c}$ & $65.1 \pm 1.3 b$ \\
\hline & $\mathrm{CT}$ & $0.68 \pm 0.05 \mathrm{c}$ & $55.92 \pm 3.43 \mathrm{c}$ & $90.2 \pm 0.8 \mathrm{a}$ & $81.7 \pm 12.5 \mathrm{a}$ \\
\hline \multirow[t]{3}{*}{ Red } & DS & $69.20 \pm 0.46 \mathrm{a}$ & $30.45 \pm 0.72 \mathrm{c}$ & $23.7 \pm 0.5 \mathrm{c}$ & $24.5 \pm 0.5 \mathrm{c}$ \\
\hline & PS & $10.33 \pm 0.75 b$ & $64.35 \pm 4.74 \mathrm{a}$ & $79.7 \pm 0.9 \mathrm{~b}$ & $60.0 \pm 1.0 \mathrm{~b}$ \\
\hline & $\mathrm{CT}$ & $0.09 \pm 0.01 \mathrm{c}$ & $48.56 \pm 2.95 b$ & $87.1 \pm 2.7 \mathrm{a}$ & $65.6 \pm 0.7 \mathrm{a}$ \\
\hline \multirow[t]{3}{*}{ Pink } & DS & $61.92 \pm 0.87 \mathrm{a}$ & $-11.5 \pm 0.31 \mathrm{c}$ & $349.3 \pm 0.4 \mathrm{a}$ & $40.1 \pm 0.8 \mathrm{~b}$ \\
\hline & PS & $51.15 \pm 2.61 \mathrm{a}$ & $8.89 \pm 0.48 b$ & $25.5 \pm 14.0 \mathrm{c}$ & $28.5 \pm 1.6 \mathrm{c}$ \\
\hline & $\mathrm{CT}$ & $4.68 \pm 0.07 \mathrm{~b}$ & $19.48 \pm 2.17 \mathrm{a}$ & $74.9 \pm 2.8 \mathrm{~b}$ & $70.4 \pm 1.8 \mathrm{a}$ \\
\hline \multirow[t]{3}{*}{ Blue } & DS & $34.58 \pm 0.41 \mathrm{a}$ & $66.97 \pm 2.63 \mathrm{a}$ & $311.8 \pm 0.5 \mathrm{a}$ & $16.5 \pm 0.7 \mathrm{c}$ \\
\hline & PS & $3.93 \pm 0.40 \mathrm{~b}$ & $29.2 \pm 3.04 \mathrm{~b}$ & $86.5 \pm 0.4 b$ & $63.2 \pm 0.6 \mathrm{~b}$ \\
\hline & $\mathrm{CT}$ & $-0.06 \pm 0.01 \mathrm{c}$ & $-38.60 \pm 0.54 \mathrm{c}$ & $82.0 \pm 3.2 \mathrm{~b}$ & $69.40 \pm 1.5 \mathrm{a}$ \\
\hline
\end{tabular}

${ }^{\mathrm{z}} \mathrm{DS}=$ distal petal segment; PS $=$ proximal petal segment; CT $=$ corolla tube; $h^{\circ}=$ hue angle.

${ }^{\mathrm{y}}$ Different letters $(\mathrm{a}-\mathrm{c})$ in columns denote statistically significant differences in each parameter among different flower segments of an individual primrose cultivar by least significant difference (LSD) test at $P<0.05$.

were considered statistically significant. Results are presented as mean values with $\mathrm{SE}$.

\section{Results}

COLORIMETRIC PARAMETERS AND PIGMENT DISTRIBUTION IN DIFFERENT FLOWER SEGMENTS. The lightness of a plant sample is defined by the $L^{*}$ parameter, and the comparison among different flower segments revealed that the CT was significantly lighter than the other two segments, regardless of the cultivar analyzed. This can be related to an additional characteristic of the CT, namely, the low $a^{*}$ value. On the other hand, DS of the red and PS of the pink hybrid primrose flowers were defined by highest $a^{*}$ (and low angle of $h^{\circ}$ ), which marks red coloration. Correspondingly, high $b^{*}$ parameter defines the yellowness of a sample, and the petals of 'Golden Yellow 566' hybrid primrose were characterized by highest $b^{*}$ among the cultivars analyzed in the present study. Moreover, the hue angle of all segments was comparable in the yellow cultivar (Table 3).
Chlorophyll b predominated over chlorophyll a in all flower segments of analyzed hybrid primrose cultivars. Total chlorophyll levels were highest in the $\mathrm{CT}$ and ranged from 0.126 to $0.242 \mu \mathrm{g} \cdot \mathrm{mm}^{-1}$. On the other hand, PS of all hybrid primrose cultivars was characterized by highest amounts of total carotenoids (Table 4).

The HPLC chromatogram of hybrid primrose petal extracts measured at $530 \mathrm{~nm}$ yielded 16 different peaks: one delphinidin glycoside, two cyanidin glycosides, four petunidin glycosides, four peonidin glycosides, three malvidin glycosides, and two rosinidin glycosides. Glucose and galactose were the prevalent sugars, and several compounds had two sugar moieties (hexosides) linked to the aglycones (Table 1). Most compounds were tentatively identified for the first time in P. ×hybrida flowers.

No anthocyanins were detected in yellow-flowered specimens. On the other hand, blue petals accumulated 12 diverse anthocyanins, and six and seven different glycosides of cyanidin, peonidin, and rosinidin were detected in pink and red primrose petals, respectively. For clearer presentation of the results, the content of anthocyanin groups is presented in Table 5 , and the distribution of major individual compounds in different-colored primrose cultivars is only reported in text. Blue hybrid primrose was characterized by delphinidin-3glucoside, petunidin-3-galactoside, petunidin-3-glucoside, malvidin dihexoside, malvidin-3-galactoside, malvidin-3glucoside, dimethyl petunidin dihexoside, and dimethyl petunidin hexoside, which were not detected in other $P$. $\times$ hybrida flowers. Moreover, cyanidin-3-galactoside and rosinidin hexoside were only identified in red hybrid primrose. Pink cultivar accumulated several anthocyanins, which were also present in red or purple primrose (Table 5).

Table 4. Chlorophyll a and b, total chlorophyll, total carotenoids, and total pigments measured in three flower segments of four hybrid primrose cultivars.

\begin{tabular}{|c|c|c|c|c|c|c|}
\hline \multirow[b]{2}{*}{ Color } & \multirow[b]{2}{*}{ Flower segment $^{\mathrm{z}}$} & Chlorophyll a & Chlorophyll b & Total chlorophyll & Total carotenoids & Total pigments \\
\hline & & \multicolumn{5}{|c|}{$\left[\right.$ mean \pm SE $\left.\left(\mu \mathrm{g} \cdot \mathrm{mm}^{-2}\right)\right]$} \\
\hline \multirow[t]{2}{*}{ Yellow } & DS & $0.034 \pm 0.007 \mathrm{c}^{\mathrm{y}}$ & $0.073 \pm 0.015 \mathrm{~b}$ & $0.106 \pm 0.023 \mathrm{~b}$ & $0.063 \pm 0.008 \mathrm{c}$ & $0.169 \pm 0.028 b$ \\
\hline & PS & $0.053 \pm 0.005 \mathrm{~b}$ & $0.071 \pm 0.010 \mathrm{~b}$ & $0.124 \pm 0.015 \mathrm{ab}$ & $0.188 \pm 0.010 \mathrm{a}$ & $0.312 \pm 0.023 \mathrm{a}$ \\
\hline \multirow[t]{3}{*}{ Red } & DS & $0.066 \pm 0.018 \mathrm{~b}$ & $0.045 \pm 0.030 \mathrm{~b}$ & $0.112 \pm 0.109 \mathrm{~b}$ & $0.055 \pm 0.007 \mathrm{c}$ & $0.261 \pm 0.063 \mathrm{~b}$ \\
\hline & PS & $0.099 \pm 0.009 \mathrm{a}$ & $0.148 \pm 0.016 \mathrm{a}$ & $0.247 \pm 0.025 \mathrm{a}$ & $0.175 \pm 0.007 \mathrm{a}$ & $0.422 \pm 0.028 \mathrm{a}$ \\
\hline & $\mathrm{CT}$ & $0.101 \pm 0.007 \mathrm{a}$ & $0.141 \pm 0.014 \mathrm{a}$ & $0.242 \pm 0.021 \mathrm{a}$ & $0.117 \pm 0.005 \mathrm{~b}$ & $0.359 \pm 0.023 \mathrm{ab}$ \\
\hline & PS & $0.056 \pm 0.005 \mathrm{a}$ & $0.076 \pm 0.010 \mathrm{a}$ & $0.132 \pm 0.015 \mathrm{a}$ & $0.074 \pm 0.006 \mathrm{a}$ & $0.206 \pm 0.019 \mathrm{a}$ \\
\hline & $\mathrm{CT}$ & $0.052 \pm 0.005 \mathrm{a}$ & $0.074 \pm 0.010 \mathrm{a}$ & $0.126 \pm 0.015 \mathrm{a}$ & $0.033 \pm 0.002 \mathrm{~b}$ & $0.158 \pm 0.016 b$ \\
\hline \multirow[t]{3}{*}{ Blue } & DS & $0.036 \pm 0.009 \mathrm{~b}$ & $0.148 \pm 0.075 \mathrm{a}$ & $0.174 \pm 0.068 \mathrm{ab}$ & $0.035 \pm 0.002 \mathrm{c}$ & $0.146 \pm 0.028 \mathrm{~b}$ \\
\hline & PS & $0.053 \pm 0.007 \mathrm{ab}$ & $0.088 \pm 0.016 \mathrm{~b}$ & $0.141 \pm 0.024 b$ & $0.092 \pm 0.003 \mathrm{a}$ & $0.233 \pm 0.024 \mathrm{a}$ \\
\hline & CT & $0.070 \pm 0.010 \mathrm{a}$ & $0.121 \pm 0.022 \mathrm{ab}$ & $0.192 \pm 0.032 \mathrm{a}$ & $0.049 \pm 0.004 \mathrm{~b}$ & $0.241 \pm 0.035 \mathrm{a}$ \\
\hline
\end{tabular}

${ }^{\mathrm{z}} \mathrm{DS}=$ distal petal segment; PS $=$ proximal petal segment; $\mathrm{CT}=$ corolla tube.

${ }^{\mathrm{y}}$ Different letters $(\mathrm{a}-\mathrm{c})$ in columns denote statistically significant differences in each parameter among different flower segments of an individual primrose cultivar by LSD test at $P<0.05$. 
Table 5. The content of anthocyanin groups in different flower segments of red, pink, and blue hybrid primrose cultivars.

\begin{tabular}{|c|c|c|c|c|}
\hline \multirow[b]{3}{*}{ Anthocyanin group/compound } & \multirow[b]{3}{*}{ Color } & \multicolumn{3}{|c|}{ Flower segment $^{z}$} \\
\hline & & DS & PS & CT \\
\hline & & \multicolumn{3}{|c|}{$\left[\right.$ mean $\left.\pm \mathrm{sE}\left(\mu \mathrm{g} \cdot \mathrm{g}^{-1} \mathrm{FW}\right)\right]$} \\
\hline \multirow[t]{3}{*}{ Cyanidin glycosides } & Red & $325.8 \pm 36.5 \mathrm{a}^{\mathrm{y}}$ & $35.5 \pm 4.4 \mathrm{~b}$ & $8.0 \pm 1.4 \mathrm{~b}$ \\
\hline & Pink & $59.4 \pm 10.9 \mathrm{~b}$ & $131.9 \pm 25.9 \mathrm{a}$ & $73.8 \pm 7.1 \mathrm{a}$ \\
\hline & Blue & $57.7 \pm 5.7 \mathrm{~b}$ & $5.7 \pm 2.0 \mathrm{~b}$ & $9.6 \pm 2.6 \mathrm{~b}$ \\
\hline \multirow[t]{3}{*}{ Delphinidin-3-glucoside } & Red & - & - & - \\
\hline & Pink & - & - & - \\
\hline & Blue & $26.5 \pm 3.9$ & $8.3 \pm 1.8$ & $9.4 \pm 2.2$ \\
\hline \multirow[t]{3}{*}{ Petunidin glycosides } & Red & - & - & - \\
\hline & Pink & - & - & - \\
\hline & Blue & $45.9 \pm 9.1$ & $17.8 \pm 4.7$ & $32.2 \pm 7.4$ \\
\hline \multirow[t]{3}{*}{ Peonidin glycosides } & Red & $2,586.3 \pm 111.1 \mathrm{a}$ & $271.8 \pm 9.0 \mathrm{~b}$ & $43.3 \pm 2.7 \mathrm{~b}$ \\
\hline & Pink & $789.4 \pm 175.5 b$ & $1,143.8 \pm 135.4 \mathrm{a}$ & $486.1 \pm 153.5 \mathrm{a}$ \\
\hline & Blue & $108.0 \pm 16.1 \mathrm{c}$ & $30.3 \pm 4.4 \mathrm{~b}$ & $42.1 \pm 8.3 \mathrm{~b}$ \\
\hline \multirow[t]{3}{*}{ Malvidin glycosides } & Red & - & - & - \\
\hline & Pink & - & - & - \\
\hline & Blue & $68.7 \pm 14.7$ & $31.7 \pm 7.0$ & $86.1 \pm 12.1$ \\
\hline \multirow[t]{3}{*}{ Rosinidin glycosides } & Red & $5.7 \pm 0.8 \mathrm{a}$ & $0.45 \pm 0.07 \mathrm{~b}$ & $0.07 \pm 0.04 \mathrm{a}$ \\
\hline & Pink & $14.2 \pm 6.5 \mathrm{a}$ & $11.4 \pm 3.8 \mathrm{a}$ & $0.4 \pm 0.2 \mathrm{a}$ \\
\hline & Blue & - & - & - \\
\hline \multirow[t]{3}{*}{ Sum of anthocyanins } & Red & $3,330.8 \pm 140.9 \mathrm{a}$ & $332.4 \pm 10.8 b$ & $52.7 \pm 2.9 \mathrm{c}$ \\
\hline & Pink & $862.9 \pm 187.8 b$ & $1,287.1 \pm 158.2 \mathrm{a}$ & $570.1 \pm 160.7 \mathrm{a}$ \\
\hline & Blue & $888.4 \pm 51.6 \mathrm{~b}$ & $148.7 \pm 19.5 \mathrm{~b}$ & $233.4 \pm 52.5 \mathrm{~b}$ \\
\hline
\end{tabular}

${ }_{\mathrm{z}} \mathrm{DS}=$ distal petal segment; PS = proximal petal segment; $\mathrm{CT}=$ corolla tube; $\mathrm{FW}=$ fresh weight. ${ }^{\mathrm{y}}$ Different letters $(\mathrm{a}-\mathrm{c})$ in columns of an individual flower segment denote statistically significant differences in each anthocyanin group among different primrose cultivars by LSD test at $P<0.05$.

Flower segments of a specific cultivar always contained the same anthocyanins, but their content differed among the segments. DS of red primroses accumulated significantly higher levels of all identified anthocyanin groups compared with the other two color hybrids and were particularly abundant in peonidin-3-galactoside and peonidin dihexoside 2 (Table 5). Similarly, PS of pink hybrid primrose contained highest amounts of peonidin-3-galactoside, peonidin dihexoside 1, and cyanidin-3-glucoside and consequently, the highest sum of anthocyanins among the PS of the cultivars analyzed.

FlaVONOL Distribution AND TPC IN DIFFERENT FLOWER SEGMENTS. Six groups of flavonols were detected in different flower segments of four hybrid primrose cultivars, and forty individual compounds were tentatively identified in total (Table 2). Glucose, rutinose, and galactose were linked to quercetin, kaempferol, myricetin, syringetin, isorhamnetin, and laricitrin, which were frequently acylated. Di- and tri-hexosides were determined in all cultivars (Table 2). Yellow primrose was characterized by the greatest diversity of flavonols as it contained four isorhamnetin, five kaempferol, six laricitrin, three myricetin, six quercetin, and six syringetin glycosides (30 flavonols in total), but their sum was significantly lower in all flower segments compared with the other three cultivars (Table 6). Blue, red, and pink hybrid primrose contained 29, 24, and 22 different flavonols, and their distribution varied significantly among the flower segments. Glycosides of quercetin were the most abundant flavonols in all flower segments, with the exception of DS and PS in the yellow hybrid, which were characterized by highest amounts of laricitrin glycosides. Only seven flavonols were detected in all flower segments of all cultivars analyzed, and generally, a specific flavonol profile was characteristic for each flower segment. The highest sum of all flavonols was determined in DS of the red hybrid primrose $\left(11,294 \mu \mathrm{g} \cdot \mathrm{g}^{-1} \mathrm{FW}\right)$ and the lowest in the CT of the yellow hybrid $\left(386 \mu \mathrm{g} \cdot \mathrm{g}^{-1} \mathrm{FW}\right)$.

Correspondingly, red DS segments were characterized by the highest TPC compared with the other flower segments of the red hybrid primrose and other cultivars analyzed (Fig. 3). TPC was always lowest in the CT (GAE from 213 in yellow to $381 \mathrm{mg} /$ 100 g FW in pink hybrids), significantly higher in PS (GAE from 517 in yellow to $924 \mathrm{mg} / 100 \mathrm{~g} \mathrm{FW}$ in pink hybrids), and highest in DS of the primrose petal (GAE from 1078 in yellow to $1830 \mathrm{mg} / 100 \mathrm{~g} \mathrm{FW}$ in red hybrids). The pattern can be correlated with a similar distribution of anthocyanins and flavonols in various flower segments.

\section{Discussion}

Colorimetric Parameters AND PIGMENT DISTRIBUTION IN DIFFERENT FLOWER SEGMENTS. A common perception of the Primula genus is their yellow flower; however, color polymorphism of $P$. vulgaris (Richards, 2003; Shipunov et al., 2011) and crosses with other primrose species have yielded astonishing red, purple, orange, and blue hues of the hybrid primrose. Differences in color parameters were significant among the three flower segments, and most particularly, the CT was characterized by highest $L^{*}$ and lowest $a^{*}$. The latter marks green to purple hues of a plant sample and is higher in red, pink, or blue flowers (Kumpanenko et al., 2014; Schmitzer et al., 2010). It is therefore not surprising that DS of the red and PS of the pink hybrid primrose flowers were defined by highest $a^{*}$.

The level of total chlorophyll in the CT was comparable with the levels detected in developing bracts of several poinsettia (Euphorbia pulcherrima) cultivars (Slatnar et al., 2013), and Unal et al. (2003) previously measured considerable levels of total chlorophyll in corolla and pedicel of $P$. vulgaris. The perianth of most flowering plants contains low amounts of chlorophyll and performs photosynthesis. Aschan and Pfanz (2006) and Yamamizo et al. (2011) reported that pale green $P$. xpolyantha accumulates carotenoids and chloroplasts during all stages of petal development. Moreover, christmas rose flowers accumulate substantial levels of chlorophylls, which are functionally integrated into the thylakoid membrane and effectively contribute to the overall photosynthesis (SalopekSondi et al., 2002). It may therefore be speculated that higher levels of total chlorophyll in the CT are linked to the location, which is nearest to the developing seeds. Similarly, successful pollination of christmas rose flowers stimulated the production of chloroplasts in adjacent sepals (Schmitzer et al., 2013). 
Table 6. The content of flavonol groups in different flower segments of four hybrid primrose cultivars.

\begin{tabular}{|c|c|c|c|c|}
\hline \multirow[b]{3}{*}{ Flavonol group } & \multirow[b]{3}{*}{ Color } & \multicolumn{3}{|c|}{ Flower segment ${ }^{\mathrm{z}}$} \\
\hline & & DS & PS & $\mathrm{CT}$ \\
\hline & & \multicolumn{3}{|c|}{$\left[\right.$ mean \pm SE $\left.\left(\mu \mathrm{g} \cdot \mathrm{g}^{-1} \mathrm{FW}\right)\right]$} \\
\hline \multirow[t]{4}{*}{ Quercetin glycosides } & Yellow & $2,418.3 \pm 210.5 \mathrm{~d}^{\mathrm{y}}$ & $848.1 \pm 131.9 \mathrm{~b}$ & $102.9 \pm 23.5 \mathrm{~b}$ \\
\hline & Red & $7,235.5 \pm 253.1 \mathrm{a}$ & $3,180.1 \pm 230.6 \mathrm{a}$ & $534.8 \pm 110.9 \mathrm{~b}$ \\
\hline & Pink & $6,356.8 \pm 186.9 b$ & $3,711.6 \pm 112.8 \mathrm{a}$ & $456.9 \pm 71.9 \mathrm{~b}$ \\
\hline & Blue & $5,089.5 \pm 330.1 \mathrm{c}$ & $3,182.8 \pm 304.9 \mathrm{a}$ & $1,483.5 \pm 385.4 \mathrm{a}$ \\
\hline \multirow[t]{4}{*}{ Kaempferol glycoside } & Yellow & $367.8 \pm 23.8 \mathrm{c}$ & $135.9 \pm 15.9 \mathrm{~d}$ & $33.9 \pm 2.7 \mathrm{c}$ \\
\hline & Red & $2,039.0 \pm 104.2 \mathrm{~b}$ & $895.2 \pm 45.8 \mathrm{~b}$ & $159.8 \pm 23.6 \mathrm{~b}$ \\
\hline & Pink & $763.2 \pm 84.8 \mathrm{c}$ & $479.5 \pm 43.5 \mathrm{c}$ & $84.8 \pm 9.1 \mathrm{c}$ \\
\hline & Blue & $3,015.7 \pm 517.9 \mathrm{a}$ & $1,505.4 \pm 104.7 \mathrm{a}$ & $298.5 \pm 34.8 \mathrm{a}$ \\
\hline \multirow[t]{4}{*}{ Myricetin glycosides } & Yellow & $938.6 \pm 107.8 \mathrm{a}$ & $390.1 \pm 68.2 \mathrm{a}$ & $35.6 \pm 10.1 \mathrm{~b}$ \\
\hline & Red & - & $121.1 \pm 15.2 \mathrm{~b}$ & $23.7 \pm 4.2 \mathrm{~b}$ \\
\hline & Pink & $40.5 \pm 6.0 \mathrm{~b}$ & $91.0 \pm 12.6 \mathrm{~b}$ & $7.4 \pm 2.7 b$ \\
\hline & Blue & $758.4 \pm 76.0 \mathrm{a}$ & $317.7 \pm 57.3 \mathrm{a}$ & $86.8 \pm 17.9$ a \\
\hline \multirow[t]{4}{*}{ Syringetin glycosides } & Yellow & $1,064.7 \pm 99.3 \mathrm{a}$ & $586.2 \pm 50.9 \mathrm{a}$ & $86.4 \pm 12.4 \mathrm{a}$ \\
\hline & Red & - & $392.6 \pm 29.1 \mathrm{~b}$ & $94.2 \pm 12.1 \mathrm{a}$ \\
\hline & Pink & - & $44.7 \pm 2.7 \mathrm{c}$ & $18.6 \pm 1.9 \mathrm{~b}$ \\
\hline & Blue & $102.7 \pm 15.2 b$ & $2.9 \pm 0.7 \mathrm{c}$ & $6.9 \pm 2.4 b$ \\
\hline \multirow[t]{4}{*}{ Isorhamnetin glycosides } & Yellow & $520.0 \pm 65.4 \mathrm{c}$ & $179.8 \pm 33.9 \mathrm{c}$ & $41.5 \pm 9.1 \mathrm{~b}$ \\
\hline & Red & $2,019.7 \pm 140.3 b$ & $1,346.4 \pm 61.2 \mathrm{a}$ & $289.4 \pm 46.6 \mathrm{a}$ \\
\hline & Pink & $2,400.0 \pm 144.0 \mathrm{a}$ & $1,275.9 \pm 46.4 \mathrm{a}$ & $209.8 \pm 20.2 \mathrm{a}$ \\
\hline & Blue & $186.3 \pm 46.0 \mathrm{~d}$ & $427.2 \pm 94.1 \mathrm{~b}$ & $203.8 \pm 57.0 \mathrm{a}$ \\
\hline \multirow[t]{4}{*}{ Laricitrin glycosides } & Yellow & $2,313.2 \pm 62.3 \mathrm{a}$ & $1,063.9 \pm 85.7 \mathrm{a}$ & $86.3 \pm 14.1 \mathrm{a}$ \\
\hline & Red & - & $367.2 \pm 23.6 \mathrm{~b}$ & $87.4 \pm 12.5 \mathrm{a}$ \\
\hline & Pink & - & $88.3 \pm 13.9 \mathrm{c}$ & $17.5 \pm 4.7 \mathrm{~b}$ \\
\hline & Blue & $215.9 \pm 31.3 b$ & $133.5 \pm 15.8 \mathrm{c}$ & $58.3 \pm 16.5 \mathrm{a}$ \\
\hline \multirow[t]{4}{*}{ Sum of flavonols } & Yellow & $7,622.6 \pm 392.2 \mathrm{c}$ & $3,204.2 \pm 322.8 b$ & $386.6 \pm 62.7 \mathrm{c}$ \\
\hline & Red & $11,294.2 \pm 154.3 \mathrm{a}$ & $6,302.6 \pm 293.5 \mathrm{a}$ & $1,189.4 \pm 200.3 b$ \\
\hline & Pink & $9,560.5 \pm 405.4 \mathrm{~b}$ & $5,691.0 \pm 145.8 \mathrm{a}$ & $795.1 \pm 107.1 \mathrm{c}$ \\
\hline & Blue & $8,526.2 \pm 578.0 \mathrm{bc}$ & $5,569.6 \pm 426.9 \mathrm{a}$ & $2,137.7 \pm 505.4 \mathrm{a}$ \\
\hline
\end{tabular}

${ }_{\mathrm{z}} \mathrm{DS}=$ distal petal segment; $\mathrm{PS}=$ proximal petal segment; $\mathrm{CT}=$ corolla tube; $\mathrm{FW}=$ fresh weight.

${ }^{\mathrm{y}}$ Different letters $(\mathrm{a}-\mathrm{d})$ in columns of an individual flower segment denote statistically significant differences in each flavonol group among different primrose cultivars by Duncan's multiple range test at $P<0.05$.

Petal segments of the analyzed cultivars contained considerable amounts of carotenoids, and Yamamizo et al. (2011) also reported from 10 to more than $270 \mu \mathrm{g} \cdot \mathrm{g}^{-1} \mathrm{FW}$ total carotenoids in yellow and pale green petals of Primula species at different stages of flower development. Primula heterochroma leaves reportedly contain lower amounts of carotenoid pigments (Noroozisharaf et al., 2015), and similar data have been published on $P$. veris and $P$. vulgaris leaves (Medvegy et al., 2005).

Sixteen glycosides of anthocyanins were detected in different cultivars and petal segments of the hybrid primrose, and many were tentatively identified for the first time. As early as 1930, Scott-Moncrieff isolated primulin (malvidin-3-galactoside) from magenta and dark red flowers of $P$. xpolyantha (ScottMoncrieff, 1930) and also determined small amounts of delphinidin- and cyanidin-based anthocyanins. Later, Harborne and Sheratt investigated the composition of $P$. sinensis flowers, which reportedly contained malvidin-, petunidin-, cyanidin-, and pelargonidin-based pigments, but no glycosides of delphinidin or rosinidin (Harborne and Sherratt, 1961). Specifically, malvidin3-glucoside and petunidin-3-glucoside were characteristic for purple flowers, which is in accord with our data on blue flowering Primula. Orange-red genotypes predominately accumulated pelargonidin-3-glucoside, peonidin-3-glucoside, and low amounts of cyanidin-3-hexoside (Harborne and Sherratt, 1961). Again, a similar composition was detected in red hybrid primrose analyzed in our study, with the exception that no pelargonidin glycosides could be confirmed in their petal segments. The presence of malvidin-3,5-diglucoside in $P$. viscosa and $P$. integrifola, delphinidin-3,5diglucoside in $P$. obconica, and hirsutidin-3,5-diglucoside in $P$. hirsuta flowers has also been reported (Harborne and Sherratt, 1961).

Until now, no one has focused on studying the composition of various flower segments of Primula species. In most studies, the yellow centers and the CT were removed before analysis, or the whole flowers were analyzed. The results of our study indicate that identical anthocyanins are characteristic for all flower segments of a particular cultivar, but their content differs significantly among the DS, PS, and CT. Generally, DS accumulated highest levels of total anthocyanins with the exception of the PS of the pink-colored hybrid. The latter was also the darkest part of the pink flower according to the parameter $\mathrm{L}^{*}$, which is in tight correlation with anthocyanin composition of plant tissue (Kumpanenko et al., 2014; Schmitzer et al., 2010).

Although blue-flowered cultivar seemed visually the darkest among the analyzed primrose hybrids, this characteristic was not explicitly expressed neither in its $\mathrm{L}^{*}$ parameter (it was namely comparable with the red hybrid) nor in its high anthocyanin content. This corresponds to the report of Shipunov et al. (2011), who also detected no significant differences between dark pink and blue-violet $P$. vulgaris flowers. Possibly, the methylated forms of petunidin glycosides, which prevail in blue-flowered primrose, produce a darker visual perception, which is also stimulated by high diversity of anthocyanin forms. Methylation of anthocyanins has been reported as one of the important reasons for the shift of color hues in addition to the type and abundance of aglycones and sugar moieties linked to the basic C6-C3-C6 carbon skeleton (Zhao and Tao, 2015).

Anthocyanin content in hybrid primrose flower segments was negatively correlated with their chlorophyll levels, which is in accordance with the study of Ünal et al. (2003) who measured decreased levels of chlorophyll at concurrent increase of total anthocyanins in $P$. vulgaris. The arrest of chlorophyll synthesis also was reported by Kannangara and Hansson (1998) and Ayala Arreola et al. (2008) after the activation of anthocyanin biosynthetic pathway in developing poinsettia bracts.

Flavonol distribution AND TPC IN DIFFERENT FLOWER SEGMENTS. Forty different flavonols were detected in hybrid 


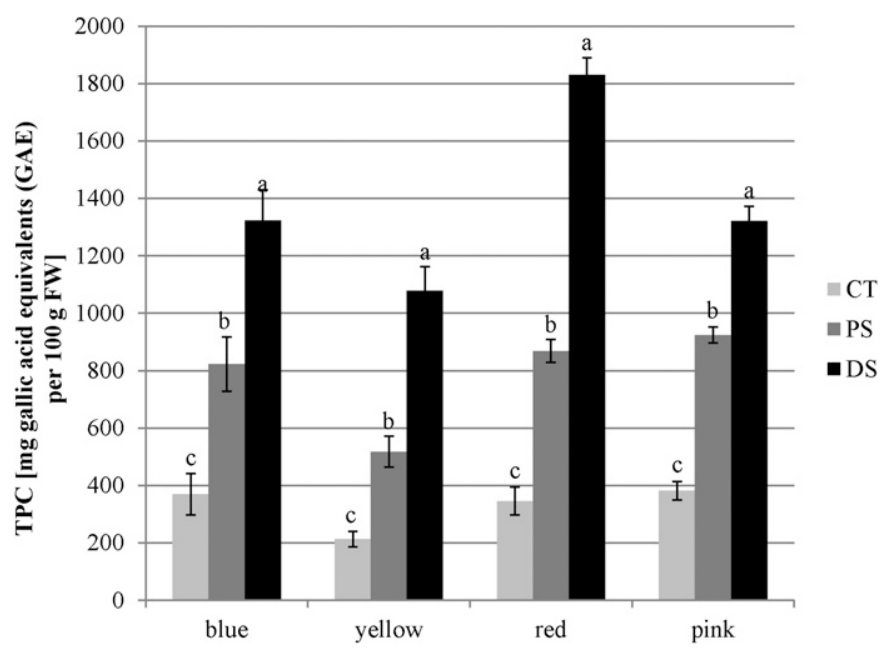

Fig. 3. Total phenolic content of blue, yellow, red, and pink hybrid primrose cultivars determined in three flower segments. Mean \pm SE $[\mathrm{mg}$ gallic acid equivalents (GAE) per $100 \mathrm{~g} \mathrm{FW]}$ are presented, and the differences in TPC among flower segments (DS = distal petal segment; PS = proximal petal segment; and CT = corolla tube) of each individual cultivar are denoted with letters above the bars. Duncan's multiple range test $(P<0.05)$ was used for data analysis.

Primula flower segments. El Morchid et al. (2014) detected 65 flavonoids in $P$. veris flowers but may have overestimated their total number. Nevertheless, they similarly reported the presence of quercetin dihexoside, kaempferol-3-glucoside, isorhamnetin-3-rutinoside, and isorhamnetin-3-glucoside in different plant organs. Moreover, Vitalini et al. (2011) reported quercetin, kaempferol, and isorhamnetin as the most common aglycones in leaves of the Primula genus and different sugar moieties (glucose, rhamnose, xylose, and galactose) linked to their 3-position. Noroozisharaf et al. (2015) measured from 166 to $980 \mu \mathrm{g} \cdot \mathrm{g}^{-1} \mathrm{FW}$ quercetin-3-glucoside in leaves of various $P$. heterochroma accessions, which is significantly lower than the content detected in hybrid primrose DS. Flavonoids have previously been used as chemotaxonomic markers in various Primulaceae species (Fico et al., 2007; Valant-Vetschera et al., 2010; Vitalini et al., 2011), and the distinct flavonol distribution in hybrid primrose cultivars suggests a similar potential. However, their content and diversity are highly dependent on the environment and physiological stages of the plant tissue (El Morchid et al., 2014; Schmitzer et al., 2010). As all hybrid primrose flowers were sampled in identical developmental stage (fully opened flowers from the middle part of the plant rosette) and plants were potted in the same substrate and grown in the same conditions, these effects were minimized.

Total phenolic content of hybrid primrose flowers has never been evaluated previously. However, Noroozisharaf et al. (2015) measured GAE from 541 to $1272 \mathrm{mg} / 100 \mathrm{~g} \mathrm{FW}$ total phenols in leaves of various germplasm accessions of $P$. heterochroma, which is comparable with the flowers of the hybrid primrose.

\section{Conclusions}

The field of genetic breeding strives to produce astonishing new primrose hybrids, which are mainly differentiated by their specific flower color. Color patterns and phenolic distribution are tightly interconnected, and they significantly define the ornamental potential of cultivated plants. Until now, the hybrid primrose has not been evaluated in terms of anthocyanin and flavonol profiles, which characterize their specific flower color. The petals are frequently bicolored and contain different anthocyanins and flavonols; moreover, they are characterized by relatively high levels of chlorophyll, particularly in the CT and proximal flower segments. The diversity of anthocyanin and flavonol aglycones suggests that exciting new hybrids could be introduced with localized gene silencing, and striped or blotched hybrid primroses may decorate our environments in the future.

\section{Literature Cited}

Aschan, G. and H. Pfanz. 2006. Why snowdrop (Galanthus nivalis L.) tepals have green marks? Flora 201:623-632.

Ayala Arreola, J., A.M. Castillo González, L.A. Valdez Aguilar, M.T. Colinas León, J. Pineda Pineda, and E. Avitia García. 2008. Effect of calcium, boron and molybdenum on plant growth and bract pigmentation of poinsettia. Rev. Fitotec. Mex. 31:165-172.

Cunja, V., M. Mikulic-Petkovsek, F. Stampar, and V. Schmitzer. 2014. Compound Identification of selected rose species and cultivars: An insight to petal and leaf phenolic profiles. J. Amer. Soc. Hort. Sci. 139:157-166.

El Morchid, E.M., P.T. Londono, M. Papagiannopoulos, L. GobboNeto, and C. Müller. 2014. Variation in flavonoid pattern in leaves and flowers of Primula veris of different origin and impact of UV-B. Biochem. Syst. Ecol. 53:81-88.

Eugster, C.H. and E. Markifischer. 1991. The chemistry of rose pigments. Angew. Chem. Intl. Ed. Engl. 30:654-672.

Fico, G., G. Rodondi, G. Flamini, D. Passarella, and F. Tomé. 2007. Comparative phytochemical and morphological analyses of three Italian Primula species. Phytochemistry 68:1683-1691.

Harborne, J.B. and H.S.A. Sherratt. 1961. Plant polyphenols. 3. Flavonoids in genotypes of Primula sinensis. Biochem. J. 78:298306.

Huck, C.W., C.G. Huber, K.H. Ongania, and G.K. Bonn. 2000. Isolation and characterization of methoxylated flavones in the flowers of Primula veris by liquid chromatography and mass spectrometry. J. Chromatography 870:453-462.

Kannangara, G.G. and M. Hansson. 1998. Arrest of chlorophyll accumulation prior to anthocyanin formation in Euphorbia pulcherrima. Plant Physiol. Biochem. 36:843-848.

Kumpanenko, I.V., A.V. Roshchin, N.A. Ivanova, A.V. Bloshenko, N.A. Shalynina, and T.N. Korneeva. 2014. Colorimetry: Choice of colorimetric parameters for chromophore concentration measurements. Russ. J. Gen. Chem. 84:2295-2304.

Markelov, I.N., D.B. Gelashvili, A.I. Shirokov, and A.A. Nizhegorodtsev. 2015. Prospects of using geometric indications of the corolla of the cultural forms of the flowered primrose Primula $\times$ polyantha Miller, 1768 (Primulaceae, Magnoliópsida) for bioindication purposes. Biol. Bull. 42:911-916.

Marks, S.C., W. Mullen, and A. Crozier. 2007. Flavonoid and chlorogenic acid profiles of English cider apples. J. Sci. Food Agr. 87:719-728.

Medvegy, A., K. Kálmán, and E. Lehoczki. 2005. Photosynthetic acclimation to light of the three taxa of a Primula vulgaris $\times P$. veris hybrid zone in the Bakony mountains. Acta Biol. Szeged. 49:157159.

Mikulic-Petkovsek, M., J. Rescic, V. Schmitzer, F. Stampar, A. Slatnar, D. Koron, and R. Veberic. 2015. Changes in fruit quality parameters of four Ribes species during ripening. Food Chem. 173:363-374.

Mori, M., K. Yoshida, Y. Ishiqaki, T. Matsunaga, O. Nikaido, K. Kameda, and T. Kondo. 2005. UV-B protective effect of a polyacylated anthocyanin, HBA, in flower petals of the blue morning glory, 
Ipomoea tricolor cv. Heavenly Blue. Bioorganic Medicinal Chem. 13:2015-2020.

Morozowska, M. 2004. Vegetative development, flowering, fruiting and saponin content in cultivated cowslip (Primula veris L.) plants. Herba Polonica 50:28-35.

Müller, A., M. Ganzera, and H. Stuppner. 2006. Analysis of phenolic glycosides and saponins in Primula elatior and Primula veris (primula root) by liquid chromatography, evaporative light scattering detection and mass spectrometry. J. Chromatography 1112:218-223.

Noroozisharaf, A., H. Samizadeh Lahiji, A. Hatamzadeh, and D. Bakhshi. 2015. Phytochemical attributes of endemic endangered primrose (Primula heterochroma Stapf.) accessions grown in Iran. Physiol. Mol. Biol. Plants 21:573-581.

Richards, J. 2003. Primula. BT Batsford, London, UK.

Salopek-Sondi, B., M. Kovac, T. Prebeg, and B. Magus. 2002. Developing fruit direct post-floral morphogenesis in Helleborus niger L. J. Expt. Bot. 53:1949-1957.

Schmitzer, V., M. Mikulic-Petkovsek, and F. Stampar. 2013. Sepal phenolic profile during Helleborus niger flower development. J. Plant Physiol. 170:1407-1415.

Schmitzer, V., R. Veberic, G. Osterc, and F. Stampar. 2010. Color and phenolic content changes during flower development in groundcover rose. J. Amer. Soc. Hort. Sci. 135:195-202.

Scott-Moncrieff, R. 1930. Natural anthocyanin pigments: The magenta flower pigment of Primula polyanthus. Biochem. J. 24:767-778.

Shipunov, A., Y. Kosenko, and P. Volkova. 2011. Floral polymorphism in common primrose (Primula vulgaris Huds., Primulaceae) of the northeastern Black Sea coast. Plant Syst. Evol. 296:167-178.
Singleton, V.L., R. Orthofer, and R.M. Lamuela-Raventos. 1999. Analysis of total phenols and other oxidation substrates and antioxidants by means of folin-ciocalteu reagent. Methods Enzymol. 299:152-178.

Slatnar, A., M. Mikulic-Petkovsek, R. Veberic, F. Stampar, and V. Schmitzer. 2013. Anthocyanin and chlorophyll content during poinsettia bract development. Sci. Hort. 150:142-145.

Sood, S. and P.K. Nagar. 2003. Changes in abscisic acid and phenols during flower development in two diverse species of rose. Acta Physiol. Plant. 25:411-416.

Ünal, M., S. Yentür, G. Cevahir, M. Sarsağ, and T. Kösesakal. 2003. Physiological and anatomical investigation of flower colors of Primula vulgaris L. Biotechnol. Biotechnol. Equip. 17:102-108.

Valant-Vetschera, K.M., T.D. Bhutia, and E. Wollenweber. 2010. Chemodiversity of exudate flavonoids in Dionysia (Primulaceae): A comparative study. Phytochemistry 71:937-947.

Vitalini, S., G. Flamini, A. Valaguzza, G. Rodondi, M. Iriti, and G. Fico. 2011. Primula spectabilis Tratt. aerial parts: Morphology, volatile compounds and flavonoids. Phytochemistry 72:1371-1378.

Wellburn, A.R. 1994. The spectral determination of chlorophyll a and chlorophyll b, as well as total carotenoids, using various solvents with spectrophotometers of different resolution. J. Plant Physiol. 144:307-313.

Yamamizo, C., M. Hirashima, S. Kishimoto, and A. Ohmiya. 2011. Carotenoid composition in the yellow and pale green petals of Primula species. Bul. Natl. Inst. Floricult. Sci. 11:67-72.

Zhao, D.Q. and J. Tao. 2015. Recent advances on the development and regulation of flower color in ornamental plants. Front. Plant Sci. 6:1-13. 